\title{
Memory, Forgetfulness and Narration: Reminiscence to Recall Victims of the Armed Conflict in Colombia
}

\author{
Alejandro Riascos Guerrero \\ Corporacion Universitaria Minuto de Dios, Centro Regional Pasto ${ }^{1}$
}

\begin{abstract}
As a result of years of internal armed conflict in Colombia, the people who suffered and still suffer from conditions of war, recognized as victims or survivors, even support the effects of traumatic events in violent acts. Countless efforts from research and psychological intervention, face the demands of the subjects that make up the populations of victims who are spread throughout the country. This paper presents preliminary, some reflections resulting from the literature review of research papers working to build historical memory as an interventional device and research that allows to establish parameters really necessary to build peace in the territory Colombian, as well as approximate the conditions and needs that victims have the psychic level subjects and the communities where they are organized. A critical reflection is proposed, starting from the psychoanalysis theory, Which Allows to formulate a position for research in Differentiated esta field. ${ }^{2}$
\end{abstract}

Keywords: Memory, psychic trauma, victim, armed conflict, narrative, history, psychoanalysis.

\section{Introduction}

The socio-political situation and scenario it goes across Colombia, given the history of internal armed conflict, involves a number of needs for the communities that have borne the brunt of the war. While on reparation for victims, the government shows a series supported on figures that are held in repair material and financial, in contrast results, another series of studies showing another disturbing picture yet sensitive as a result of formulated violence that communities suffer at the hands of the various actors in the conflict. There are documented and varied evidence showing alarming figures against diagnoses such as depression, anxiety and post-traumatic stress in populations victims of armed conflict in Colombia.

This research approaches the manifestations of social and individual malaise afflicting the victims of armed conflict particularly in Pasto, pertenenciente territory the Department of Nariño region in the south western Colombia, which historically has been hit by the scourge of war. It is recognized that violence begets serious consequences on mental health, bringing together a number of impacts on the individual, family and social matters which are beyond the response capabilities of the victims communities. In this sense, the research work of a thoughtful review of existing reports and intervention in the context of psychosocial care for victims of armed conflict research, realize the ways in which we have been working with this population.

This paper presents an advance level document review of the research project "Building memory, narrative and subjective redress victims of armed conflict in Pasto" which is part of the assumption of acts of war as a social catastrophe, and whose justificatory livelihood in the deep effects in the country, as a result of armed conflict and the role of state institutions over civilian life, victims and territory.

\section{Methodology}

${ }^{1} \mathrm{Mg}$. (C) Psychoanalysis subjectivity and culture. National university of Colombia. Psychologist, University of Nariño. Teaching Psychology Research Program Regional Center UNIMINUTO Pasto, a member of the research group GISE. Member Forum Pasto Lacanian Psychoanalysis field.

Contact: ariascosgue@uniminuto.edu.co. Cel: (+57) 3425311730

2Partial results Project: Building memory, narrative and subjective redress victims of armed conflict in Pasto (Colombia). Project supported by the Corporacion Universitaria Minuto de Dios. 
For the research project, a joint methodological qualitative (Bonilla, E., Rodriguez, p. 2005) research and psychoanalysis (Gallo, 2002) proposes an ethical perspective of treatment for the victims, about their experiences, the social fabric, memory and history, under current regulations especially the 1448 Act 2011 or Act Victims and Land Restitution; provision whose content poses and defines measures of care, assistance and comprehensive victims of gross violations of human rights and breaches of international humanitarian law in the context of internal armed conflict repair and effective enjoyment of the right of victims to truth, justice, reparation and guarantees of non-repetition.

\section{Document analysis method}

As for document review, it was decided to initially identify research and interventions conducted within the framework of psychosocial care to victims, the above in order to establish procedural, instrumental and methodological level forms of approximation of researchers and psychology professionals for the purpose of the proposed study. The analysis units were all documents on the topic of psychosocial approach to victims of armed conflict, and psychological interventions with the same population. Consulted documentary bases, Scoupus, Lantindex, Publindex, Scielo, Redalyc, provide information and articles for the revision work. "Psychosocial care", "psychosocial intervention", "trauma of war", "armed conflict", "mental health", "victims", "Colombian armed conflict" and "mental health: as search criteria, the following descriptors were included problems". These descriptors were combined in different ways when scanning with the aim of expanding the search criteria.

Similarly, it took as a reference psychoanalytic theory for reflection against the revised documents. In this regard, it seeks to establish a differential panorama against forms of approach proposed from psychosocial perspectives in the context of attention to victims of armed conflict in Colombia, to provide a methodological perspective to the ongoing investigation, enabling rescue methodological level, some principles that come from psychoanalysis.

\section{Discussion}

\section{Memory and Forgetting: interventive regulatory conditions and practices.}

We crossed a time in the national context in which prevails, despite political tensions, a program aimed at overcoming the internal armed conflict discourse. In this discursive order the signifier memory, has had a leading role in the framework of the demobilization of paramilitary groups, the peace process with the FARC, and future, throughout the transitional justice framework. The Colombian government and the institutions that represent it, as well as non-profit organizations, victims' associations, researchers, both human sciences and other areas of knowledge, have taken responsibility for the approach, reconstruction and treatment of memory and its inescapable relationship with history, as part of the consolidation of a necessary process, under the knowledge of the truth, and as a way to ensure social justice and non-repetition. The State relating to realize efforts to lay the legal basis for the construction of historical memory in the country, can be traced from Law 975 of 2005, which hosts some guidelines on that component. In this sense, was the work of the Group of Historical Memory in collaboration with the National Center for Reparation and Reconciliation, history of important processes and initiatives within the framework of the demobilization of paramilitary groups Act 1448 of 2011 or the law of victims, specifically stipulates the conditions, legal, political and administrative provisions necessary to establish a framework towards the construction of historical memory of the country, by an entity specified official order.

Reception, retrieval, preservation, collection and analysis of all documentary material, oral testimony and any other means concerning violations committed during the internal armed conflict, through the conduct of investigations, activities museum, educational and other related contributing to establish and clarify the causes of such phenomena, know the truth and help prevent future repetition of the facts. "(Ministry of Justice, 2011, p.2).

Under this legal framework, the work of the National Center for Historical Memory oriented purposes aimed at meeting the state goals related to overcoming the conflict, issued a series of reports on the historical conditions of the war in Colombia, and from them brand also, a sheet of methodological route for the collection and treatment of documented information. These efforts aim to contribute to the knowledge of historical truth, which takes as a reference for its construction, all stakeholders (victims, social organizations, victims, etc.) and the contributions they can do through non-judicial mechanisms, for this purpose. This work is not only necessary to symbolically compensate the victims, but also, It allows to set parameters related to legal truth and ensure investigation and prosecution of the perpetrators or perpetrators. (National Center of Historical Memory, 2014). 
Under this scenario in the department of Nariño, as a historically affected by armed conflict region have developed multiple community work memory, which are documented in reports and portals of the National Center of Historical Memory, which reflect the results of this type experiences. One of the flagship within the memory work in Nariño references, is "La Casa de la Memoria" in Tumaco (N). Still, there is little information on the forms, practices and procedures that were used in the work memory developed in the region, which prevents there an approach to the methodologies used and their effects on communities, beyond what reported in official documents.

In this regard it should be mentioned that in the field of historical memory work also converge various other government initiatives, which bring together a number of interpretations and notions about the politics of memory and how they should be worked; these are grounded in research and built on theoretical trends interventions that address greater extent, by memory in their collective version, as a result of intersubjective and social relations that compromise complex joints historical, political and cultural level. (Aguilar-Forero, 2018).

If take into account that part of the raw material needed for this purpose, emerges from the narratives of experiences, facts and victims experienced by subjects events; the staging of such testimony, involves the appearance of another phenomenon, the order of the subjective, it is necessary to analyze carefully. Narratives are fragments of subjective history that seek to organize, classify, represent and document effectively, to establish the truth of what happened, from the singular reminder to the construction of collective memory. In this process, it is possible to intuit that the evocation of the particular history, does not emerge in isolation, but is accompanied by the associated events suffered in the context of a traumatic event of war affections. This emotional effect committed in the testimonial remembrance of a traumatic event, is recognized, has a cutting effect, in some scenarios for the work of the construction of historical memory as a collective, given the high emotional content and the subjective effort that it even leads to silence, to the impossibility of representation in language, and therefore to a break in the narrative that the subject is expected. (Torralba, 2015).

In this vein, several questions open before this particular phenomenon: all subjects victims are willing to contribute their story building scenarios promoted by governmental and non-governmental organizations? Are there intentions of the actors involved in the field of historical memory, which go beyond the objective of its construction and produce what is known as action damage in populations? What role in the process of building collective historical memory, the subject's position against its own story and testimonial demand?

The above questions are also relate to specific and defined those involved in this field actions. Government guidance has defined a number of general guide mechanisms, against the construction work of historical memory, which enable participation and financial support for different social organizations, private entities or initiatives that drive actions victims memory. While the above is correct, given the need to listen to the many voices and sectors involved in historical events of the war, also it opens the possibility that this scenario is seen as a niche market, if the construction of historical memory is assumed to be a form of social intervention (Moreno Molina Camacho \& Valencia, 2018).

In this perspective, the proliferation of both investigations or interventions that treat or are intended to study the historical memory in Nariño, promotes the meeting of different ways to take and interpret policies that organize such practices, generating including ruptures, tensions and conflicts; In this regard, there will be initiatives aimed at functional work on memory according to the dominant economic partner discourse, and other initiatives that emerge in response to the sense proposed and given historical memory, in favor of a built sense, consensual and that makes resistance to versions of the story provided by the institutions, from the social organization (Soley \& Vargas, 2014). These initiatives, depending on the speech that guide the ways of intervening, They have concomitant effects their actions, in the subjects involved in the construction of historical memory. Therefore, if one considers that the approach, intervention and construction of historical memory, engages both the individual and the collective as elements that affect each other, and include institutional logic to this scenario, governmental and non- governmental, social, economic and even political interests, it is possible to say that there are different discourses on the construction of historical memory that guide initiatives, methodological and interventive practices and results collective and individual level in the context of working with victims of armed conflict.

\section{Time and return of the traumatic: between reminiscence and reminiscence}

The scene is the dimension of history.

History always has a character of staging. 
J.Lacan (1962-1963)

Perhaps, initially the quote serves overture, at first sight has no direct relationship with the document title, however, if the worked subject approaches the consequences of war, then it also includes a reflection on the traumatic; the purpose of the appointment is justified while always tells a story and particular scene in psychoanalysis, which corresponds to what is unique to each subject, and allows locate traumatic as a specific and distinct event, despite to originate in collective conditions. Thus I introduce the framework to address traumatic corresponds to the coordinates position subjects in conditions of war, rather the psychological effects of her subjects,

In this sense, reflection is in the circumstances that relate specifically to Colombia's internal armed conflict. The effects of these conditions on subjects who suffered the rigor of the conflict, allow a critical reading on the temporary insistence of reality tied to how traumatic it insists, and that perpetuates their psychic effects, sometimes hand therapeutic practices and clinics, advocating the revival of war experiences through discourse.

Then, it is first necessary to deal with the trauma as a concept: According to the DSM-5, trauma is defined as any situation in which a person is exposed to scenes of actual or imminent death, serious physical injury or sexual assault, either as a direct victim, close to the victim or witness. The ICD-11, soon to be published, conceptualizes it as any exposure to a stressful situation of an exceptionally threatening or horrifying nature that is likely to produce a deep malaise in most people. This conceptualization allows us to place a particular framework from which the traumatic event is approached from psychology,

In this regard, and in keeping the work of psychosocial court that are made on this phenomenon, the traumatic event is approachable specifically in two ways: one corresponding to its registration in the language, ie, it is through the discourse of the victims in which case, realizes the impact of a violent event in the life of one who suffered. Another is by its effects, ie individual symptoms or groups, which arise as a result of trauma; This latter aspect approaches the Lacanian definition regarding the way how we approach the traumatic event. Still, this idea is not new if we return to the Freudian premise of the trauma in hysteria, this approach places the trauma as an initially inassimilable event for the ego of a subject, far from being able to react properly,

Precisely because of not having been prepared, Aristizabal et al (2012) describe how as traumatic element is housed dormant and can at a second time, which is not predictable, be reactivated causing symptom production. This mainly appears in the writings concerning the treatment of hysteria Freud, who by 1983 raises the existence of a temporal distance between the emergence of a traumatic event and producing symptoms. Temporal distance that the subject suffers from the memory trace left by that event, but which is housed in the unconscious due to defensive psychic effort seeks to avoid discomfort to the subject. Might wonder at this point why revisit this postulate, which it seems outdated given the current considerations facing the trauma; However, its use is justified because today in Colombia, the interventional and research approach to the trauma of war survivors subjects clearly reflects that the testimonial account taken as an instrument for the construction of historical memory, for example, revives the psychic effects of the subject who staged his story of a traumatic event. Reminiscence of these events, overflows again the possibilities of subjective response, allowing sense to remember and recount as interventional exercise in the framework of the intervention or investigation with victims of armed conflict, is not enough. If consider that there is a temporary lapse, between the irruption of the traumatic event and the causation of the symptoms, it could be said that these two times, allow to establish that there is an imbalance in the subject that is relative to its history, while the violent event marks a before and after, which requires another type of attention beyond oral repetition in certain scenarios.

Viewed this way, from the writings that deal with the subject of war in Freud (1915-1932), "of war and death, current issues" or "Why the war" human conflict is approached from reading its effects, the cruelty of their methods and techno-scientific relationship for the destruction of the other, either as a defense or attack. Without any doubt, this tradition even in today's wars is maintained. The consequences of war, -the effects of traumatic events to be precise in the combatants or civilians who are in the midst of confrontation, keep the calls lasting echoes of catastrophes of war. For Colombian civilians, the affections of terror, which accompanies the feeling of risk of loss of life as a result of torture, attack, displacement, displacement, or forced disappearance of relatives, constitute the framework of the collective history of war, but also keep in themselves, the particularity that is built from the traumatic event. 
Traumatic events (regardless of origin) occurred in the history of a subject, as we know, left in the psyche a psychic imprint, which remains dormant, and in particular conditions, produces a range of effects depending on the affect associated with the memory thereof, following the Freudian postulate. Same that can be traced in reading the experience of pain in the "Project Scientific Psychology" (Freud, 1950) since there is a similar question of trauma consideration, $i$ is it not the experience of pain, a historical fact that leaves a mark and save some temporary location, if you will, in the history of a subject? One might think about it, it is unlikely that an individual can once again in his memory, the first experience of pain, however this event, conceived in a mythical time, that is outside the scope of an accurate temporary location, but whose effects we know about in the post, in a historical period. Myth, in this case allows knotting more precisely the question of trauma following the postulate of Lacan in the $\mathrm{X}$ seminar on Anguish. I raise this, formulated in terms of history, it presents the articulation of the significant elements of signifying chains that allow the establishment of a script for a particular scene, from which it lives and experience the world. Therefore what is called reality, resulting from the production of meanings that give the frame to the scene, appoints its characters and promotes the network of relationships which together form a story (Lacan, 1962). In this sense, mythical or as originating in the scene, it is in the order of the impossible, of the unrepresentable, however it is the foundational destiny of the subject: this time for Soler (2017) "Historically it has declined in terms of misery, impotence and inability, and has been attributed to the gods or sin. Lacan recognized there the effect of the structure of language on living". In this way, the subject suffers a trauma, an event of reality that "would rather be thought of as impossible to avoid for the speaking beings that are immersed in the imaginary and the symbolic" (Soler, 2017 p.2) constitutive event is the very existence of language, and at the same time cutting and irremediably separates the subject from its object of desire, that I on the irrepresentable of the emerging to take significant body. The presence of absence of the object (a) precisely directs the script of the scene around a vacuum, which is blurred after the presence of said imaginary object $\mathrm{i}(\mathrm{a})$.

In this sense, his place in history subjective, a violent event in a context of war, subject to a noncombatant? It takes the place of a milestone in the scene, a monument of remembrance; an encounter with the real, which occurs as a result of a discontinuity in the script built imaginary via a violent interruption in the scene, which marks the subject of irremediable manner. If the initial continuity of the scene is marked by the object to be missing, the fortuitous emergence of a violent event promotes the fall of imaginary veil, resulting in agonizing answer: "I could speak of" encounter with reality "only if we consider that this meeting is always failed because, in so far as it is possible to resume the story, it becomes missing. "(Sanfelipo, 2010 p.440)

On the other hand, if trauma is defined in terms of breakthrough, surprise or exterior appearance of an item as an event, it will be understood beyond the violence that emerges, ie, the fortuitous factor has an effect, as it involves the subjectivity of who experiences ${ }^{1}$. In this sense, we can say that the traumatic event is the scope of representation is the temporal logic of the effect retrospectively, an issue that differentiates the advent of true original, which was discussed above and explained in Lacan, trauma. In this sense what is representable in the course of history subjectively, both past-present temporal relationship is the traumatic event, which in the case of victims of armed conflict in Colombia, located in the witness a form of symbolization, as long as it is taken as part of the signifying chain that is part of the unique history of each victim and is not taken from the imaginary uptake and idenficacion with the horror of the story, which suspends subjects in reminiscence,

While this reading is not new today, it is always necessary, by virtue of the existence of clinical practice oriented treatment guided by identification with the horror of facts narrated by the victims or seeking appeasement of symptoms from the incessant play on different stages of their stories. The narrative, as testimony exists as a form of opposition to oblivion, however in this case, is not sufficient as a form of symbolic elaboration of a violent event that has marked the history of a subject in the course of the war; It means rather the return of pain associated with memory, repetition in reminiscence, in favor of conscious acceptance of the facts, and the presumption of forgetfulness without subjective consequences.

In this sense, the reflection from psychoanalysis, also allows to place an ethical difference in relation to other clinical practices, it reverts to a position that is the effect of a construction that occurs in the experience of analysis, and It gives rise to a particular listener against the discourse of the subject who suffers, reaching a deep reading of the way as they

\footnotetext{
${ }^{1}$ It is possible that in the course of certain violent events in the conflict, subjects have witnessed, or have been affected by acts of war, however a response at the level of discomfort or symptoms is not set. In this regard, the importance of content and subjective interpretation of the fact that the link with the traumatic event, viable symptomatic expression explained.
} 
emerge through language subjective discomforts, going beyond the act of speech as a mere reproduction of narrative history.

\section{Construction of historical memory, considerations in the context of psychosocial care for victims of armed conflict.}

Clearly the initiatives, actions and strategies involved in the process of construction of historical memory in Pasto will have effects on the subjects involved, communities, and the social context of the region, which can be evaluated positively, since these scenarios They tend by knowledge of historical, necessary for the panorama of peace that has come to Colombia truth. However and since these processes address the memory of human groups in particular need to also question the place in this scenario the unique memory and mental and emotional for victims, so traces a concern also underline on ways of developing traumatic that will be part of the collective historical memory, but which is, in turn, the intimate and symbolic picture of the subject that gives his testimony regarding institutional methodological practices that mediate so that these elements emerge. It sharpens complexity of the subject when taking into account the multiplicity of nuances that add, understandings, interpretations, meanings and speeches around the politics of memory. At first, the policies refer to the number of state rules governing, order and establish social conditions, nevertheless it exists in the field of historical memory, another way of understanding these policies, such as: It sharpens complexity of the subject when taking into account the multiplicity of nuances that add, understandings, interpretations, meanings and speeches around the politics of memory. At first, the policies refer to the number of state rules governing, order and establish social conditions, nevertheless it exists in the field of historical memory, another way of understanding these policies, such as: It sharpens complexity of the subject when taking into account the multiplicity of nuances that add, understandings, interpretations, meanings and speeches around the politics of memory. At first, the policies refer to the number of state rules governing, order and establish social conditions, nevertheless it exists in the field of historical memory, another way of understanding these policies, such as:

Acts, exercise, social practices that can be institutional or non-institutional, rigid or flexible, and even hegemonic, but also against hegemonic. The latter sometimes are intentional and are guided by the desire to understand or justice, as an ethical claim and resistance "comfortable stories". At other times they are more spontaneous result of memories remain muted yet and break in unpredictable ways.(Aguilar-Forero, 2018, p.113)

This approach allows us to understand that there are differences in the way how the politics of memory are assumed in the case of Pasto, which also implies the existence of multiple initiatives, methodological approach, and interventional they have based on their actions, with such interpretations oriented discourse. You can sustain the validity of the above, on the need for plural and flexible historical building, still memory approaches this also promotes "struggles" between the visions that have built different interventional actors. Therefore, there are also risks, given the multiplicity of interpretations of the politics of memory, not only shocks that may exist between versions of the story that emerge from them, but in the way in which the communities that contribute their stories and memories for that purpose.

According to this premise, and taking up the work of historical memory as a way to intervene in the social fabric, it is recalled that the stage of psychosocial intervention, as referred to actions working for interdisciplinary way mitigate the needs of the population victims of the armed conflict, not going through its best moment (Villa Gomez, Machado Barrera, Arroyave Pizarro, \& Montoya Betancur, 2017). One of the main problems identified in this field corresponds to the contextualization of proposals and projects implemented and advance with communities of victims of armed conflict, and which have only an axis of knowledge from the document review, livelihood theoretical and under the premise of the application of universalizing methodologies, a fact that prevents generate real possibilities of transforming the social fabric, and promoting turn other negative consequences for victims, emerging from the practices that do not have knowledge the real needs of the target communities.(Insuasty Villa Gomez \& Rodriguez, 2017). In this regard, technical knowledge, and posture of intervention agents, away from knowing communities take a leading role to the detriment of the role the voices of communities, which are silenced and outside the precepts methodologically guide psychosocial interventions(Villa Gomez, 2013).

These peculiarities are not far from what happens in the context of the construction of historical memory in Nariño, since they are at one end, practices become, in the state administrative and regulatory landscape, running exercises instrumental methodologies, guided by the accumulated from the perspective of expert knowledge, and the need to comply with specific objectives and obligations of the State to the victims know. The existence of boxes methodological tools for memory initiatives and actions established by the National Center for Historical Memory, could account for a partial implementation of the process. In fact, being concentrated knowledge of methodological procedure on the construction of historical memory 
in a government entity, the debate over who controls or directs the historical memory of the country, also acquired in the political debate, a particular hue, depending on the logic discursivas government in charge(Aguilar-Forero, 2018).

While attention to the relevant and positive nature of the construction processes of historical memory in the region is put at the beginning of this section, we have at this point, a number of elements which denote other negative conditions concerning the effects can generate and evoke initiatives, guided by other interests or speeches, different from the construction of historical memory and symbolic reparation is expected to participating communities. For the monuments, for example, that for a long time were the resource to commemorate certain events in the context of armed conflict, they may be challenged, by virtue of its origin. When justice requires the State this form of symbolic reparation, so that the need to repair ordered by other authorities, generates processes or initiatives that do not have the perspective of the victims, they become more "decorative" element in the process of visibility that entities perform, to account for the performance of its obligations (Arenas, 2017). The same phenomenon that occurs when the concept of economic "utility" premium before the concept of benefit for subjects victims in processes of a similar nature.

In this regard, different elements have been identified analysis conditions which have been developed to build historical memory in Pasto; On one side are the difficulties posed by the emergence of the subjective effects of the acts of war victims, and what it means for collective work of historical reconstruction of the events in the conflict; differences and tensions stemming from the interpretations of the politics of memory, by those who assume the responsibility of working in this field; Finally, the discursive orientation that qualify initiatives, actions and methodologies applied to the construction of memory history, and its resonances in the communities involved in these processes. The knowledge obtained from this analysis can be considered as a significant contribution to the framework of historical memory construction actions that will be carried out in the future in the region.

\section{Conclusions}

As it can be evidenced not only mentioned briefly some considerations of psychoanalysis from memory, but also has brought into play the relationship between memory and trauma, not without purpose; both concepts can be traced to the dawn of the most important discoveries of psychoanalysis, and saved for this proposal, underlines importance. The phrase "the hysteric suffers from most of reminiscences" (Freud, 1893, p.33) located in memory, the hidden meaning of the enigmatic symptom in hysteria, and whose content, unknown to consciousness, remained unconscious given psychic defensive efforts. This teaches something about the plane in which it is considered to mind in psychoanalytic terms; The Discovery of the Unconscious also brings a break with conventional ways of understanding certain mental processes, and how they operate in subjects. Timelessness attributed to the unconscious and its capacity to accommodate the widest range of experiences of a subject from memory traces that remain after the experience, allows placing traumatic as a content necessary symbolization, for the history of a subject. However, this need not emerge from psychoanalysis as a therapeutic method, but the living subject the effects of a particular event that has been taken as traumatic and source of discomfort.

The need to understand the complex variations adopts memory processes individually historical construction and collectively under the foregoing, analysis elements and valuable theoretical reflection to answer the underlying phenomena and emerging relationships between actors victims and subjects involved. The relationship established with the trauma comes from the approaches that psychoanalysis did on the psychological consequences of the great wars. While this field, Freud provides some specific ideas about some clinical nuances, corresponding to the lingering effects of the experiences that occurred in the war, also established that the product of the catastrophes of war phenomena, They are fertile ground for inquiry and reflection from the psychoanalytical know. Understand the human dimension of armed conflicts and its devastating effects on the collective and individual levels, also assumes that the particularities of memory relationship trauma, is not only found in the unique experience of a subject affected by armed conflict, its consequences can also be evidenced in the social sphere; hence the need to know the truth of the events, recognition of the victims and work on historical memory as a way to heal symbolically, psychic traces of those who suffered the rigors of war and emerge as witnesses social catastrophe. The dimension of trauma committed in memory, in the context of the events suffered by victims in war, need social discourses that point to a historical truth, constructed from subjective narratives that are heard and constitute the basis of actions in the construction of collective memory (Bohleber, 2007).

But this implies understanding the dimension of the phenomena associated with memory experiences beyond clinical bet that psychoanalysis offered in the office. In this sense, Moreno (2015) suggests that it is possible to contribute to the 
prospects of intervention, and why not, research, theoretical basis of psychoanalysis, ethical and clinical principles that serve as sources of guidance and inspiration for practice with communities victims of armed conflict. For example, recognition of the unconscious as a different scenario involved in the field of social relations(Moreno, 2015), is part of those principles in the service of the investigation of certain phenomena, it allows for questions and formulate responses, compared with the complex relationships between the collective memories, individual memories and the effects brought into play in scenarios building historical truth, given the conditions and dialectical affectations between them.

So, the conceptual considerations briefly outlined in this section are just an outline of the theoretical component of psychoanalysis, which is susceptible removed for reflective analysis of the phenomenon raised. But equally, it is a way of constantly questioning on those aspects that compromise human discomfort, establishing possible answers from psychoanalytic knowledge in the Colombian context. Lacan (1953) proposes: "Better to resign because who can not join their horizon the subjectivity of his time" (p.308) as a poignant invitation or an ethical imperative to inquire from the discipline founded by Freud, that particular thing that marks the subjectivities in the culture, invitation to which this proposal is circumscribed, in front of the relations and phenomena that emerge in the devices of construction of historical memory in Colombia.

\section{Bibliographic references.}

[1] Bonilla, E. Rodriguez, P. (2005) Beyond the dilemma of methods: research in social sciences. Grupo Editorial Norma, 2005. Pp.424. ISBN 958-04-8542-9

[2] Gallo, H. (2002) of psychoanalytic research. Recovered in http://www.psicomundo.com/foros/investigacion/gallo.htm

[3] Ministry of Justice (2011) 4803 Agreement on 20 December 2011. Retrieved on: http://www.centrodememoriahistorica.gov.co/descargas/decretos/DECRETO_DEESTRUCTURA_DEL_CENTRO.pdf

[4] National Center of Historical Memory (2912) Justice and Peace: judicial truth and historical truth ?, Retrieved on: http://centromemoria.gov.co/wp-content/uploads/2015/07/verdad_judicial_verdad_historica.pdf

[5] Aguilar-Forero, NJC (2018). Memory politics in Colombia: initiatives, tensions and experiences (2005-2016). Critical History No.40, 68, 111-130. https://doi.org/10.7440/histcrit68.2018.06

[6] Torralba, F. (2015) Historical memory, reconciliation and post-conflict. Recovered www.raco.cat/index.php/ArsBrevis/article/download/311723/401803 p. 325

[7] Camacho Moreno, MA, \& Molina Valencia, N. (2018). Social intervention as an object of study: discourses, practices, problematizations and proposals. Digital athenea, 18 (3), 1-29.

[8] Solely, N., \& Vargas, L. (2014). Memory measures peacebuilding the case of the report's enough historical memory center. Cod. 2567363, 1-38. Retrieved from http://www.bivipas.unal.edu.co/bitstream/10720/683/1/2567363_2014.pdf

[9] Freud, S. (1929) Civilization and Its Discontents. Collected Works, Vol. XXI. Buenos Aires: Amorrortu EDRs, 1981. P. $57-139 .$.

[10] Aristizabal, S., Palace, J., Madariaga, C., Osman, H., Parra, L., Rodriguez, J., Lopez, G., (2012) Symptoms and psychological trauma victims and victimizers in the Colombian Caribbean . Vol.29 psychology from the Caribbean. ISSN 2011-7485 mail.

[11] Freud, S. (1915) of war and death, current issues. Volume XIV Amorrortu.

[12] Freud, S. (1933) Why the war?. Volume XXII. New Introductory Lectures on Psychoanalysis and other works.

[13] Freud, S. (1959) Draft Scientific Psychology. Tomo I. Psychoanalytic pre unpublished manuscripts and publications. Amorrortu.

[14] Lacan, J. (1962-1963) X Seminar anxiety, Chapter 1 "Introduction to Structure Angst" p. 11-95

[15] Soler, C. (2017) "Coming of the real" Pre-text of the International Meeting of Barcelona. Recovered in http://xcita-if-epfcl.barcelona/Documentos/Pre-textos/(Sp)Pre-text01-ColetteSoler.pdf

[16] Sanfelippo, L., (2010). Conceptualizations of trauma in Freud and Lacan. II International Congress of Research and Professional Practice in Psychology XVII Conference on Research Sixth Meeting of Researchers in Psychology of MERCOSUR. School of Psychology - University of Buenos Aires, Buenos Aires. 
[17] Aguilar-Forero, NJC (2018). Memory politics in Colombia: initiatives, tensions and experiences (2005-2016). Critical History No.40, 68, 111-130. https://doi.org/10.7440/histcrit68.2018.06

[18] Villa Gomez, JD, Barrera Machado, D., Arroyave Pizarro, L., \& Montoya Betancur, Y. (2017). Action Damage: welfarism to social construction of the victim. Look at repair processes and psychosocial intervention in Colombia. Universitas Psychologica, 16 (3), 1. https://doi.org/10.11144/javeriana.upsy16-3.adac

[19] Villa Gomez, JD, \& Insuasty Rodriguez, A. (2017). Between participation and resistance: rebuilding the social fabric from below in the municipality of San Carlos Beyond logic state reparation. Agora USB, 16 (2), 453. https://doi.org/10.21500/16578031.2442

[20] Villa Gomez, JD (2013). Horizontality, shared knowledge expression and psychosocial processes focus on support to victims of political violence in Colombia. Agora USB, 13 (1), 289. https://doi.org/10.21500/16578031.91

[21] Arenas, S. (2017, May 9) Sandra Arenas. Symbolic repair. [Video Archive] Recovered from https://www.youtube.com/watch?v=BE0QD5A7qKE

[22]

[23] Freud, S. $(1924,1925)$ The Ego and the Id and other works. Unconscious. Volume XIV Amorrortu.

[24] Freud, S. (1920) The Psychopathology of Everyday Life. Volume VI. Amorrortu.

[25] . Rooster, H. (2004) "Forgetting and Truth" magazine since the Garden of Freud Recovered in:

a. http://www.revistas.unal.edu.co/index.php/jardin/issue/view/969

[26] Gomez, G (2004) "War Injuries: memory and forgetting" magazine since the Garden of Freud. Retrieved on: http://www.revistas.unal.edu.co/index.php/jardin/issue/view/969

[27] Moreno, M. (2013). Psychoanalysis and social intervention. Retrieved on: https://www.icesi.edu.co/revistas/index.php/revista_cs/article/view/1568

[28] Perez Muñiz, Rico \& Gomez (2010) "Moving meaningless: Clinical study experience and the violent displacement" Retrieved on: https://revistas.upb.edu.co/index.php/informespsicologicos/article/view / 6100

[29] Sotelo, A. (2004) "Testimony, body, memory and forgetting" magazine since the Garden of Freud. Retrieved on: http://www.revistas.unal.edu.co/index.php/jardin/issue/view/969

[30] Freud, S. (1893) On the Psychical Mechanism of Hysterical Phenomena: Preliminary Communication. In S. Freud Works Vol. II. pp. 27-44. Buenos Aires: Routledge.

[31] Bohleber, W. (2007). Memory, trauma and collective memory: the battle for memory in psychoanalysis. Psicoanálisis APdeBA, XXIX (1), 43-75. Retrieved from https://www.apdeba.org/wpcontent/uploads/Bohleber.pdf

[32] Moreno, MA (2015). Psychoanalysis and social intervention. CS magazine (11), 115. https://doi.org/10.18046/recs.i11.1568

[33] Lacan, J. (1953) function and field of speech and language in psychoanalysis. In Jacques Lacan, Writings 1 pp.231-310. Editorial Biblioteca Nueva, S, L. 